\title{
8
}
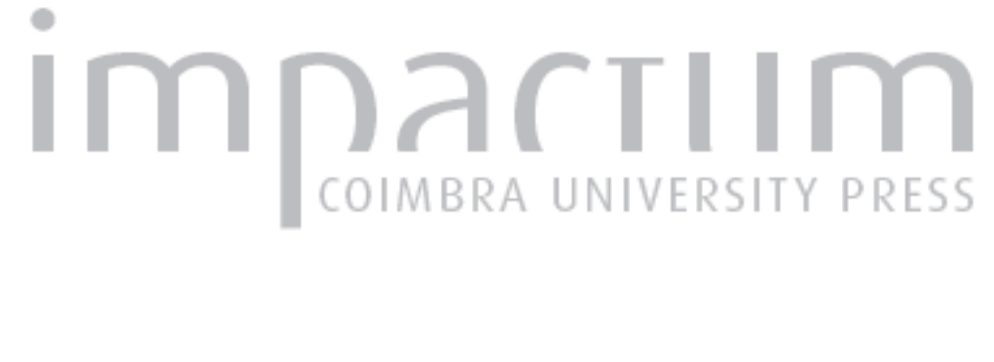

\section{Regulação participada e regulação em parceria como resposta aos desafios da profissẵo}

Autor(es): $\quad$ Miranda, João

Publicado por: Imprensa da Universidade de Coimbra

URL persistente:

URI:http://hdl.handle.net/10316.2/43895

DOI:

DOI:https://doi.org/10.14195/2183-5462_32_3

Accessed : $\quad$ 26-Apr-2023 14:55:54

A navegação consulta e descarregamento dos títulos inseridos nas Bibliotecas Digitais UC Digitalis, UC Pombalina e UC Impactum, pressupõem a aceitação plena e sem reservas dos Termos e Condições de Uso destas Bibliotecas Digitais, disponíveis em https://digitalis.uc.pt/pt-pt/termos.

Conforme exposto nos referidos Termos e Condições de Uso, o descarregamento de títulos de acesso restrito requer uma licença válida de autorização devendo o utilizador aceder ao(s) documento(s) a partir de um endereço de IP da instituição detentora da supramencionada licença.

Ao utilizador é apenas permitido o descarregamento para uso pessoal, pelo que o emprego do(s) título(s) descarregado(s) para outro fim, designadamente comercial, carece de autorização do respetivo autor ou editor da obra.

Na medida em que todas as obras da UC Digitalis se encontram protegidas pelo Código do Direito de Autor e Direitos Conexos e demais legislação aplicável, toda a cópia, parcial ou total, deste documento, nos casos em que é legalmente admitida, deverá conter ou fazer-se acompanhar por este aviso.

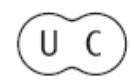




\section{Mediasornalismo}

ÉTICA JORNALÍSTICA PARA O SÉCULO XXI NOVOS DESAFIOS, VELHOS PROBLEMAS

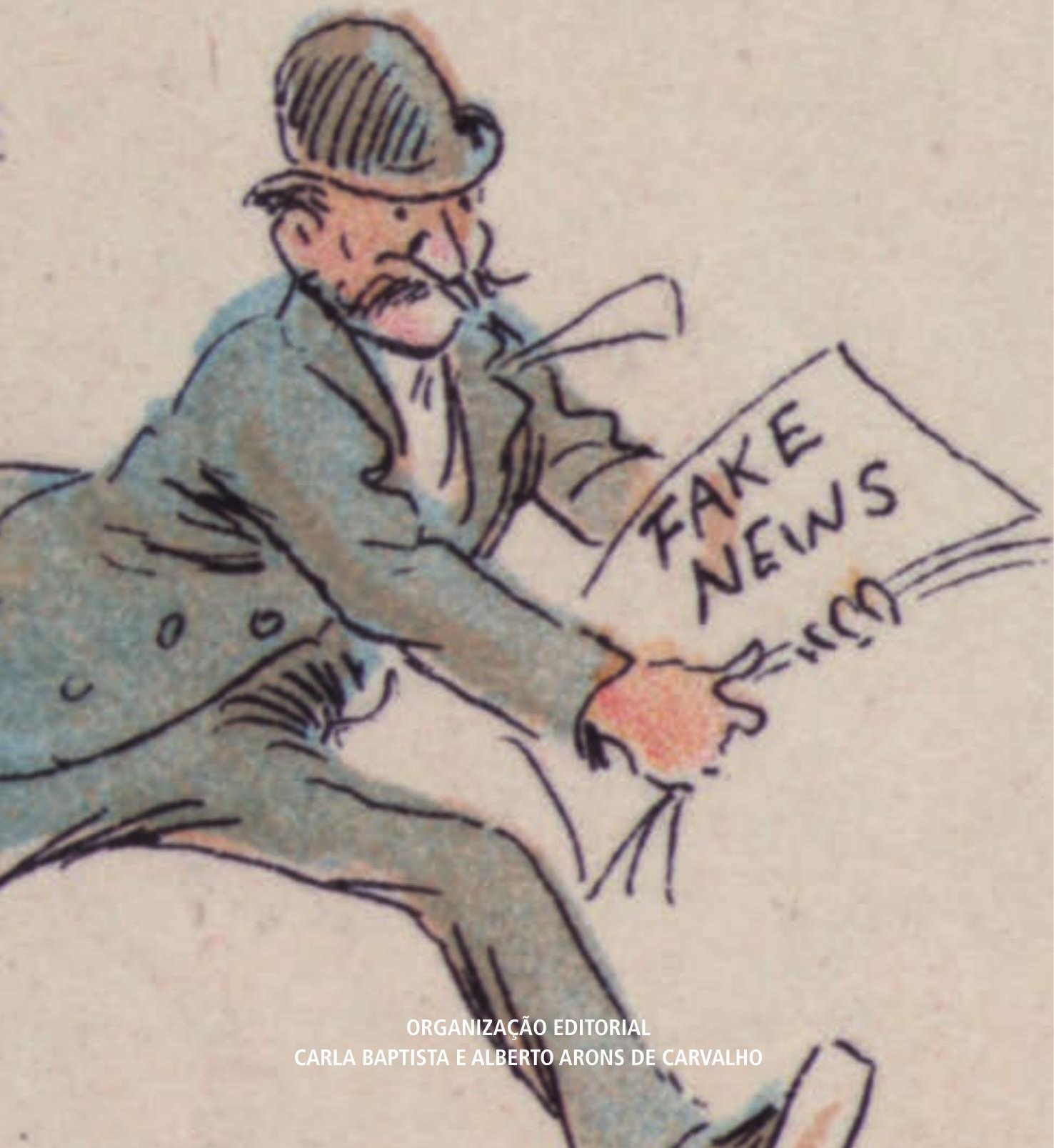




\title{
REGULAÇÃO PARTICIPADA E REGULAÇÃO EM PARCERIA COMO RESPOSTA AOS DESAFIOS DA PROFISSÃ $0^{1}$
}

\author{
Participated REgulation ANd REgulatory PARTNERShip IN RESPONSE tO THE \\ CHALLENGES FACING THE PROFESSION
}

REgULACIÓN PARTICIPADA Y REGULACIÓN EN COLABORACIÓN COMO RESPUESTA A LOS

DESAFÍOS DE LA PROFESIÓN

JOÃO MIRANDA

Universidade de Coimbra. Faculdade de Letras. 3000-370 Coimbra, Portugal.

CEIS20

joaomsantosmiranda@gmail.com

Artigo por convite/Article by invitation/ Artículo por invitación

\section{Resumo}

Tomando como referência o processo inacabado e indefinido de consolidação da identidade profissional dos jornalistas, e o complexo enquadramento do sistema de regulação do jornalismo português, este artigo procura propor dois novos conceitos. "Regulação participada" pretende compreender concetualmente todos os espaços normativos que contam com a participação formal de jornalistas. "Regulação em parceria" descreve soluções partilhadas entre o meio profissional e os restantes agentes do sistema mediático.

\section{Palavras-chave}

Regulação do jornalismo; Regulação participada; Regulação em parceria; Jornalismo

\section{Abstract}

Grounded on the undeveloped and unfulfilled process of journalists' professional identity and the complex framework of Portuguese journalism regulation system, this article seeks to propose two new concepts. "Participated regulation" conceptually comprises all normative spaces that count on the formal participation of journalists. "Regulatory partnership" describes shared solutions between the professional domain and the remaining actors of the media system.

KEYWORDS

Journalism regulation; Participated regulation; Regulatory partnership; Journalism

1 Este trabalho é enquadrado pela Fundação para a Ciência e a Tecnologia (FCT) através da bolsa de doutoramento FCT SFRH/BD/87020/2012. 


\section{Resumen}

Teniendo en cuenta el proceso inacabado e indefinido de la consolidación de la identidad profesional de los periodistas, y el complejo marco del sistema de regulación del periodismo portugués, este artículo plantea dos nuevos conceptos. "Regulación participada" intenta comprender conceptualmente todos los espacios normativos que cuentan con la participación formal de periodistas. "Regulación en colaboración" describe soluciones compartidas entre el medio profesional y los demás agentes del sistema mediático.

\section{Palabras clave}

Regulación del periodismo; Regulación participada; Regulación en colaboración; Periodismo

\section{INTRODUÇÃO}

A discussão e decisões que conduziram o $4^{\circ}$ Congresso dos Jornalistas Portugueses não diferiram muito das de encontros anteriores, na exigência de novas dinâmicas e espaços de autorregulação. Distinguiram-se, contudo, na definição de propostas concretas de constituição de um novo enquadramento de responsabilização do jornalismo, decorrente de um debate alargado à profissão.

Esta não é, porém, uma discussão fácil ou simples. Ela surge no seguimento de um quadro de reconfiguração permanente do sistema de regulação do jornalismo português, também apoiado numa adequação legal e formal da dimensão autonormativa, que tende a fragilizar o, já de si frágil, poder institucional dos jornalistas. A partir da profissão, o posicionamento dos jornalistas apresenta sentidos algo contraditórios. Se a posição pública, enquanto corpo profissional reflete uma inegável e permanente valorização dos lugares e normas da autorregulação, o empenho concreto dos jornalistas tende a não acompanhar essa posição. Simultaneamente, os limites e monopólio, nunca bem estabelecidos, de uma profissão fluída e de caráter aberto veem-se progressivamente desafiados por novas lógicas de mercado e por um novo ambiente comunicacional em emergência.

Tendo este contexto em perspetiva, o propósito deste texto² centra-se na proposta de dois novos conceitos: "regulação participada" e "regulação em parceria". Não pretendendo substituir termos já convencionados - como auto ou corregulação - estes conceitos pretendem completar e apoiar essa discussão, evidenciando a questão profissional do jornalismo como o problema central.

De forma a contextualizar a emergência destes conceitos, este artigo procurará enquadrar as características, problemas e desafios colocados à profissão; compreender a complexidade e contemporaneidade subjacente aos conceitos

2 Este artigo constitui-se uma versão mais extensa de uma comunicação apresentada na conferência "Ética Jornalística para o Século XXI: Novos Desafios, Velhos Problemas" e resulta de um trabalho de investigação de doutoramento, focado na caraterização da autorregulação profissional dos jornalistas portugueses, que envolve diferentes instrumentos empíricos, como um inquérito ao jornalistas portugueses, uma análise descritiva e comparativa dos diferentes organismos de regulação do jornalismo do período democrático, a análise dos pareceres desses organismos ou uma análise descritiva e comparativa de organismos europeus participados por jornalistas. 
que explicam as dinâmicas de regulação a partir dos regulados; e, finalmente, caraterizar, ainda que sucintamente, 0 intrincado sistema de regulação do jornalismo português.

\section{Problemas e desafios de uma profissão aberta}

Uma conclusão que atravessa os diferentes estudos focados nos aspetos socioprofissionais da informação refere-se ao facto de a constituição e ordenação do corpo profissional do jornalismo encerrar uma série de especificidades e ambiguidades que pendem para o distinguir de outras profissões ditas estabelecidas. As especificidades referidas decorrem do contexto tardio e inacabado em que 0 processo de afirmação e consolidação da identidade profissional dos jornalistas se inscreve (Ruellan, 1993). Em causa estão, desde logo, conflitos entre representações muito distintas de identidade e onde se contrapõem visões imbricadas numa ideia liberal de representação do jornalismo e perspetivas ligadas à vertente industrializada do ofício (Chalaby, 2003; Neveu, 2005). Este quadro de contradições será a base de um complexo percurso de estabilização das bases da profissão, marcado por tensões permanentes - a título de exemplo, relativamente ao modelo de associativismo (Aldridge e Evetts, 2003; Kremmer, 2015) ou aos moldes da formação (Folkerts, 2014) -, culminando em linhas de consolidação do corpo profissional pouco precisas ou definidas.

É, aliás, com base nesta premissa que diferentes perspetivas, sobretudo fundadas numa abordagem funcionalista do fenómeno, encontram no jornalismo um ofício incapaz ou impossibilitado de concretizar plenamente o processo de profissionalização (Waisbord, 2013). Ao invés, procuram reenquadrar a atividade e o grupo como uma "profissão subdesenvolvida" (Carey, 1974, p. 227) ou uma "semi-profissão" (Witschge e Nygren, 2009), unida por uma marcada dimensão ideológica e por algum tipo de controlo simbólico. Mas, se este nível de diferenciação tem por base a incapacidade de o jornalismo responder de forma plena aos atributos distintivos de uma profissão, ele é sobretudo resultado do caráter aberto da profissão. Um fenómeno de abertura que, como Giroux (1991: 130) argumentava num texto de referência, decorre do "mito fundador" do jornalismo: a liberdade de expressão, que "legitimando a prática do jornalismo [...] não permite aos profissionais da informação obter um estatuto distinto de qualquer cidadão revindique essa mesma liberdade". 0 monopólio da profissão não depende, pois, tanto de dispositivos legais, mas sim de um fechamento simbólico (Harrits, 2014) ou de um domínio das práticas e das rotinas inerentes à atividade (Meyers et al., 2012). É neste sentido que, abstraídos de conceções funcionalistas, autores como Neveu (2005), Rieffel (2004) ou Ringoot e Ruellan (2007) argumentam que o corpo profissional do jornalismo corresponde mais a uma identidade vaga, imprecisa ou fluída, tanto no interior como no exterior da profissão.

Se, como sugerem Ruellan (1993) ou Neveu (2005), esta imprecisão assume um potencial de renovação permanente e de convocação de uma variedade de competências e formações distintas, ela é também potenciadora de condições de fragilidade interna do grupo profissional. A noção da erosão da autoridade profissional do jornalismo não se constitui, mesmo à luz do novo século, uma novidade. É par- 
ticularmente paradigmática disso a tese de "declinismo", de Herbert Gans (2003), que apontava para uma fragilização ou desapossamento do poder profissional, relativamente a uma já passada era dourada percecionada pelos jornalistas. É, no entanto, claro que a nova conjuntura sistémica da informação vem contribuindo para uma reorganização progressiva da atividade jornalística (Deuze e Witschge, 2015).

0 mercado dos media está hoje perante um conjunto de desafios e problemas difíceis de presumir há poucos anos atrás. Como refere num editorial amplamente difundido a diretora do Guardian, "a esfera pública mudou mais radicalmente durante as últimas décadas do que durante os dois séculos precedentes" (Viner, 2017). 0 jornalismo não é exceção a essa corrente de transformações.

0 acentuar das estratégias, tradicionalmente prosseguidas pelas empresas, de concentração, financeirização e comodificação das audiências, mediáticas (Chakravartty e Schiler, 2010; Schiller, 2011; Picard, 2013), favoreceu indubitavelmente a emergência das condições de destabilização do próprio mercado (Fenton, 2015) e de aprofundamento das dinâmicas de reestruturação dos modos de produção e organização do corpo profissional, pautada por marcas de despacialização, precarização, sobreexploração e burocratização do trabalho (Reinardy, 2011; Ekdale et al., 2015; 0'Donell et al., 2016), bem como por tendências de erosão do poder profissional, diminuição do corpo profissional e polarização das situações e condições de trabalho dos jornalistas (Witschge e Nygren, 2009; Örnebring, 2016; Deuze e Witschge, 2015).

Estas condições de mudança não podem, obviamente, ser desligadas do processo mais amplo e complexo de ecologia comunicacional resultante do movimento de digitalização. Mais do que um novo canal, que o mercado mediático nunca conseguiu explorar e estabilizar, o surgimento da internet e a digitalização da comunicação vieram colocar em causa o quase-monopólio dos media no acesso ao espaço público. A emergência da web 2.0 e a proliferação de novos espaços de infomediação vieram possibilitar um universo de novas formas de produção e consumo de informação, que os meios tradicionais nunca equacionaram.

No plano da distribuição, este novo contexto tende a promover novas lógicas de concorrência e de criação de valor, bem como modelos desagregados e personalizados do consumo da informação (Siapera, 2013). No plano da produção, os efeitos não são menos intrincados. 0 quadro paradoxal da "produsage" (Bruns, 2006) deu origem a um contexto igualmente complexo de "pro-am" (Bruns, 2010), onde práticas, conteúdos e padrões profissionais e amadores se confundem, contribuindo para um hibridismo dos conteúdos e formatos (Ramonet, 2011). Mas mais do que desafiar o frágil monopólio dos jornalistas, estas dinâmicas de "produsage" acentuam uma sobreprodução de informação, onde o jornalismo se vê obrigado a competir pela atenção do público. Tal contexto pende para acentuar uma "ordem desindustrializada do jornalismo" (Siapera, 2013, p. 2) ou mesmo uma subjugação do

3 No contexto português, tanto os resultados do inquérito desenvolvido no âmbito do presente estudo, quanto os dados obtidos em outras análises (ver a este respeito Rebelo et al., 2011; Rebelo et al., 2014; Obercom, 2017) indiciam marcas de uma profissão estratificada, detioração das condições laborais, rotinas burocratizadas, relativa falta de autonomia profissional, baixas expetativas relativamente à profissão, redução do contingente profissional ou a emergência de novos atores e novos produtos. 
capitalismo jornalístico às lógicas do capitalismo digital (Garcia, 2009; 2015). Com efeito, mais do que sinais de efetiva resistência, o mercado mediático tem-se pautado, em traços gerais, por estratégias de emulação dos novos espaços e cessão do seu domínio, promovendo a "buzzficação" dos formatos informativos (Cushion, 2015), a permeabilidade do jornalismo aos domínios contíguos do entretenimento e da publicidade (Fidalgo, 2015), e a abertura dos portões que os próprios jornais deveriam guardar (Dean, 2009). Conquanto possa parecer excessiva a ideia de que reside neste cenário a morte do jornalismo (Dvorkin, 2015), certo é que ele encerra um quadro de preocupações relevantes, que imbrica num cenário concreto e palpável de opacidade dos limites e jurisdição do jornalismo.

Igualmente excessiva aparenta ser a ideia de um "Ouinto Poder" em ascensão, enquanto esfera de autoridade e influência institucional com origem nos novos espaços online. Contudo, a conceção teórica de Dutton (2009) encerra a proposta interessante de reenquadrar os espaços de infomediação emergentes como novas edificações de fruição de expressão e publicação do pensamento escrito, ocupando, portanto, a função social que Giroux encontrava no jornalismo.

Argumentamos situar-se perante toda esta conjuntura o espaço e o momento de os jornalistas iniciarem um debate concreto sobre a redefinição das fronteiras da profissão e das fundações da atividade. Não como forma de limitar as funções e papéis sociais, mas, antes pelo contrário, como forma de proteger o jornalismo da diluição no vasto universo da ecologia comunicacional em emergência, salvaguardar a identidade e marcas distintivas da profissão, e preservar a sua função social primordial, a de informar.

Algo que o crescente envolvimento dos cidadãos em fórmulas participativas de comunicação (Jenkins, 2009) deixa claro é que esta discussão não pode ficar fechada no núcleo hermético da profissão. Antes, deve envolver os diferentes intervenientes nos processos de produção e consumo do jornalismo. Acedendo a que uma função essencial das soluções de regulação participadas pelos regulados passa por conhecer as necessidades e aspirações do público e da sociedade, convocando-os para o debate sobre os media (Haraszti, 2008), importará compreender como se estruturam exatamente estas dinâmicas normativas e como podem beneficiar esse debate.

\section{REGULAÇÃO A PARTIR DOS REGULADOS: DEFINIÇÃO DE CONCEITOS}

Não obstante a crescente relevância das soluções alternativas de regulação, enquanto objeto de estudo, e a emergência de novas tendências de governance dos media (Meier, 2011; Latzer et al., 2013), os conceitos de auto e corregulação surgem ainda como termos relativamente elusivos e vagos, traduzindo um amplo quadro de disposições institucionais e perspetivas de análise distintas. No campo mais vasto dos media, a extensa revisão de literatura de Puppis (2009) reflete como ambos os conceitos assumem uma dimensão muito pouco unívoca ou fechada. No domínio estrito do jornalismo e da informação, é possível identificar na diferente literatura um recurso bastante matizado do termo "autorregulação", para capturar soluções pouco coincidentes quanto aos modos de organização, participantes ou objetivos da regulação.

Prosseguindo uma visão muito genérica do fenómeno, autorregulação pode ser aduzida a partir do conjunto de regras que orientam a atividade do jornalismo e das 
estruturas que supervisionam o cumprimento dessas normas, definidas e conduzidas pelos próprios regulados, e materializadas em procedimentos prescritivos, documentos normativos ou mecanismos e organismos de resolução de conflitos (Tambini, 2015). Enquanto que a materialização da prestação de contas do jornalismo se constitui a sua razão primordial, existem outros motivos preponderantes que justificam a sua atuação, como a promoção da qualidade da informação, proteção da liberdade editorial, contenção da ingerência externa ou ajudar o público a aceder aos media (Haraszti, 2008). De acordo com uma aceção puramente tautológica, estes modelos de atuação pressupõem a intervenção, se não exclusiva, preponderante dos atores da informação: profissionais e proprietários dos media (Berger, 2010).

Isto não significa, porém, que o termo "autorregulação do jornalismo" possa ser automaticamente lido como um processo que depende forçosamente da intervenção direta dos jornalistas. Como o demonstra o caso da Press Complaints Comission (Stanistreet, 2011), o conceito de autorregulação do jornalismo pode ser aplicado, em última análise, para descrever disposições que não incluem a participação ou representação direta dos próprios jornalistas. Contudo, a participação dos profissionais figura-se fundamental, porquanto a autorregulação pressupõe uma conceção e adequação de normas ético-profissionais, que, por via da socialização, normatização e da sua atuação, penderá para instigar ou estabelecer as bases e modelos dos outros níveis da regulação (Stapf, 2010). Ao mesmo tempo, como sugere Aznar (1999), outra função essencial da autorregulação do jornalismo passa por assegurar as condições laborais, profissionais e sociais necessárias para o cumprimento dos preceitos ético-deontológicos e das obrigações sociais inerentes à atividade.

Generalizadamente contextualizada como modelo alternativo, ou mesmo de escape, à coercibilidade formal e legal da heterorregulação e do Direito, uma das caraterísticas fundamentais da autorregulação do jornalismo assenta nos elementos de controlo simbólico, e de adesão e reconhecimento por parte dos regulados, que a solução pressupõe (Stapf, 2010).

Daqui não se deve concluir que autorregulação possua um sentido necessariamente oposto à esfera da interposição governamental. Como notam Black (1996) ou Bartle e Vass (2007), autorregulação surge predominantemente associada a um variado nível de intervenção dos Estados. E, conquanto a intermediação estatal subentenda regularmente o risco de captura institucional desses espaços (Dacre, 2012; Hulin, 2014), multiplicam-se exemplos menos intrusivos de envolvimento dos parlamentos e dos governos no incentivo à autorregulação do jornalismo, promovendo a adesão às normas, definindo critérios mínimos dessa autorregulação ou apoiando financeira e infraestruturalmente a sua atuação (Puppis et al., 2012).

Mais permeável a uma ambiguidade interpretativa, o termo corregulação intercala normalmente com linhas de "autorregulação regulada", inferindo quadros de combinação entre uma autorregulação com elementos estatutários e o envolvimento das autoridades públicas, pressupondo uma solução alternativa de regulação, que envolve esquemas de cooperação com base numa vinculação estatutária entre agentes do setor e atores exteriores, e/ou uma (re)distribuição das responsabilidades regulatórias entre espaços internos e externos ao setor (Bartle e Vass, 2005; Latzer et al., 2013). No entanto, corregulação não deve ser resumida a uma aceção binária "Estado-regulados". No universo de ordenações institucionais, reconhecem 
Bartle e Vass (2005: 33) que o termo possui significações muito mais extensas, como, por exemplo, a intervenção de leigos na regulação profissional ou a participação da sociedade civil na regulação da atividade.

É, de resto, neste sentido que avança a proposição concetual de "corregulação independente", sugerida pela Comissão sobre a Liberdade de Imprensa da África do Sul (2012: 7), que se sintetiza "num sistema de regulação da imprensa, que envolve o público e o setor, com uma intervenção predominante do primeiro, e sem a participação do Estado ou do governo". Tal conceção, materializada no seu Conselho de Imprensa, parte da busca de conferir um papel central ao público na regulação da informação, procurando suprimir o contexto de erosão da visibilidade e influência institucional dos meios de prestação de contas, e conquistar a consciência e sensibilização da sociedade para a sua função pública.

Ainda mais distante de conceções encerradas no domínio do Estado ou do setor, Bernier (2014) propõe o termo "corregulação cidadã", como forma de compreender concetualmente os diferentes movimentos de criticismo dos media estabelecidos pela profusão da web 2.0, e que vieram desafiar o centralismo ou monopólio dos meios tradicionais de responsabilização do jornalismo. Um conceito de linhas idênticas é proposto por Eberwein et al. (2013, citado por Eberwein e Porlezza, 2014), muito embora "regulação participativa dos media" dê conta de um fenómeno situado menos num plano explicitamente periférico à atividade, e mais numa dimensão que pode envolver modelos combinados entre 0 exterior e 0 núcleo da produção jornalística (Fengler et al., 2014). No entanto, ambas as perspetivas partilham a noção de que o contexto comunicacional se alterou profundamente, apagando progressivamente a barreira invisível que outrora separava a redação dos utilizadores da informação, exigindo do jornalismo uma viragem de um discurso e postura ética hermética, para uma espécie de ética aberta (Ward, 2011), obrigando-o também a abandonar visões mais anacrónicas e fechadas dos seus modelos normativos.

\section{Particularidades de uM Sistema de REgulação COMPLEXo}

Portugal possui um dos mais complexos e voláteis sistemas de regulação do jornalismo da Europa ocidental, marcado, ao longo de quatro décadas de democracia, por uma profusão de propostas e soluções efémeras e inconstantes. Sem prejuízo de um aprofundamento indispensável sobre o papel e contexto de cada uma destas experiências, das decisões emanadas ou dos níveis de relação estabelecidos entre si e com outros tipos de instrumentos de responsabilização, evidenciam-se uma série de traços distintivos que sustentam uma caraterização, mesmo que sucinta, da evolução da regulação do jornalismo português.

Desde logo, este processo evolutivo não pode ser desligado do longo período de governação ditatorial. Não obstante se possam encontrar traços de iniciativas de normatização do jornalismo no pré-25 de Abril, é este aspeto que explica o contexto tardio em que a regulação da informação portuguesa emerge, bem como pende para justificar a interposição indutiva do Estado, ante um setor ainda desestruturado e em recomposição.

Outro traço evidente do sistema de regulação português prende-se com a volubilidade dos modelos e a contínua mutação do quadro institucional. Cingindo ao âmbito 
nacional, em apenas 40 anos, identifica-se a existência de dez organismos direcionados para a regulação dos processos e conteúdos do jornalismo. Esta inconstância institucional é acompanhada por uma constante mutação do quadro legislativo.

Neste ponto são paradigmáticas as alterações do Estatuto do Jornalista e a integração do normativo deontológico no âmbito dos seus deveres, potenciando o que Camponez (2011) descreve como uma "captura" da autorregulação. De resto, reside aqui outra das particularidades do contexto regulador português, que se prende com a manutenção de competências, princípios e decisões histórica e comummente associadas ao domínio da autorregulação em espaços progressivamente heterorreguladores. Esta tendência de captura vem sendo acompanhada por um movimento de afastamento da representação setorial desses espaços reguladores - note-se, a título de exemplo, as alterações orgânicas que caraterizam a viragem do ConseIho de Imprensa para a Alta Autoridade para a Comunicação Social, e desta para a Entidade Reguladora para a Comunicação Social (ERC). Efetivamente, constata-se que não só a imprensa se mantém sob o âmbito de intervenção da heterorregulação, como corresponde a um segmento substancial da sua atuação. Simultaneamente, uma análise às decisões sobre questões do jornalismo (Miranda e Camponez, 2018) demonstra serem precisamente questões de âmbito do rigor, responsabilidade e retificação que ocupam a grande parcela da atuação da heterorregulação (muito embora, os níveis de pronunciamento sobre aspetos estritamente deontológicos se verifiquem muito abaixo do suposto pelas organizações profissionais). Tal contexto é, em primeira análise, resultado dos processos de juridificação da deontologia e de alargamento das competências da heterorregulação. Não pode, contudo, ser separado da incapacidade do meio setorial de concretizar espaços de autorregulação efetivos, capazes de reivindicar essas mesmas competências (Serrano, 2010).

Refere Arons de Carvalho (2010) que, desde os tempos dos Conselhos de Informação, outra especificidade da regulação portuguesa se refere à sua dimensão altamente parlamentarizada. Uma marca que não se apagou, podemos, inclusivamente, argumentar que se vem acentuando. Embora a constituição da ERC tenha por base uma dimensão simbólica de disrupção com a centralidade e unilateralidade dos modelos de comando e controlo, e de afirmação de linhas de independência e autonomia da regulação, as controvérsias geradas em torno do organismo, das quais os processos de nomeação dos Conselhos Reguladores arrogam maior pertinência, tendem a desafiar essa visão de autonomia.

No âmbito desta profusão de soluções salienta-se ainda, não só uma falta de articulação institucional entre os organismos, como também uma sobreposição de competências e atribuições entre os mecanismos, conduzindo mesmo à difusão de pareceres diametralmente opostos sobre os meus assuntos. Também por este prisma, assinala-se uma colisão entre soluções, da qual decorre um nível de resistência e conflito entre o domínio profissional e o domínio da heterorregulação.

É neste contexto de complexidade e fragilização do poder institucional dos jornalistas que se inscreve a discussão em torno da criação de um novo organismo autorregulador. Já aqui se observou que o empenhamento dos jornalistas na defesa e promoção da sua regulação apresenta sentidos bastante contraditórios. Tal não deve, porém, ser entendido como um desmerecimento dos elementos autonormativos da profissão. Com efeito, a posição pública dos jornalistas, enquanto corpo 
profissional, tende a sublinhar uma dimensão valorativa desses mesmos elementos.

Na linha de outras investigações, também os resultados do inquérito desenvolvido no âmbito do presente estudo confirmam esse nível de valorização dos espaços de autorregulação, assim como da participação dos jornalistas nos lugares de regulação - 93,1\% dos inquiridos refere concordar com a existência de mecanismos de autorregulação e a maioria aponta como fraca a intervenção profissional na ERC, na Comissão da Carteira ou na figura dos provedores. Já quando questionados sobre possíveis novas soluções de regulação, sublinha-se uma eleição de aspetos como a salvaguarda da garantia do cumprimento dos preceitos éticos e deontológicos, proteção da liberdade de informação e garantia das condições laborais, a que a autorregulação deve atender, sendo também conferida particular importância à participação, evidentemente dos jornalistas, mas também do público, atores jurídicos e proprietários nesses processos normativos.

\section{A "regulação participada" e a "regulação em parceria"}

Aqui chegados, consideramos ter resultado evidente a complexidade concetual que cinge 0 desenho institucional da participação dos jornalistas na regulação da informação. A miríade de enquadramentos, experiências e objetivos que justifica o recurso à trilogia auto-co-heterorregulação traduz-se num uso profundamente heterogéneo de conceitos considerados estabilizados. Simultaneamente, em face da profusão de soluções e propostas que o campo do jornalismo encerra, os conceitos de auto, co e heterorregulação servem apenas de suporte para um crescente dendrograma de novas definições - também elas empregues de forma algo heterogénea. Finalmente, parece-nos claro que o estudo do fenómeno da regulação profissional do jornalismo não se poderá reduzir à concetualização tradicional do espetro auto-heterorregulação.

É neste sentido que se propõem dois termos complementares: "regulação participada" e "regulação em parceria". Estes conceitos não pretendem substituir ou desvirtuar a terminologia convencional da investigação sobre a regulação do jornalismo, mas sim completar essa discussão, evidenciando a questão profissional como o problema central.

Tendo como referência o termo avançado por Maia (2007), "regulação participada" é aqui proposto como forma de designar as soluções de regulação do jornalismo que pressupõem a participação formal dos jornalistas, tanto no desenho das normas como na sua adjudicação.

Uma razão mais genérica que fundamenta este termo decorre da conceção de que a regulação da atividade jornalística deve necessariamente incluir os seus produtores diretos. Existem, no entanto, um conjunto de outros motivos mais específicos, que justificam esta integração dos jornalistas.

Admitindo que a regulação da informação tem como primeiro objetivo a salvaguarda da liberdade de imprensa e do seu uso responsável, a integração de normas e de uma visão ético-profissional no debate regulatório configura-se essencial. Internamente, assegura uma discussão deontológica segundo cânones profissionais. Externamente, defende a liberdade de imprensa da ingerência ou abusos de terceiros, bem como instiga um discurso e um enquadramento 
de cariz ético-deontológico, nos diferentes espaços onde ocorre a regulação da informação (Stapf, 2010).

Pautando-se as novas tendências de governance dos media por uma valorização das fórmulas alternativas de regulação (Latzer et al., 2013), a mediação profissional torna-se vital no sentido de obstar a relegação desses espaços normativos às lógicas estritamente concorrenciais e/ou corporativas do mercado. Se, como se observou, a regulação da informação encerra o potencial de promover as condições laborais e profissionais necessárias para a prossecução dos preceitos ético-deontológicos (Aznar, 1999), a participação dos jornalistas é fulcral no sentido da efetivação dessas competências.

Perante os desafios da digitalização e ecologia comunicacional, a experiência profissional configura-se fundamental na resposta a estes problemas, salvaguardando os aspetos intrínsecos à liberdade e função social do jornalismo (Hulin e Dvorkin, 2013; Gore, 2008).

Uma justificação mais significativa para a integração dos jornalistas alude à aceitação dos profissionais como fator de sucesso da regulação. Isto é, apenas com o consentimento organizado dos jornalistas pode um sistema regulador do jornalismo cumprir eficazmente as suas funções. Caso contrário, apresenta-se como um mecanismo coercivo, predisposto a esbarrar em linhas de resistência à sua atuação.

Mais do que um termo descritivo, "regulação em parceria" apresenta-se um conceito prescritivo ou propositivo de um modelo que pretende ultrapassar a ossificação de perspetivas endogâmicas da regulação profissional, reenquadrando as dinâmicas contemporâneas da governance dos media a partir de rumos de compromisso entre o núcleo profissional e as restantes esferas. Novamente, encontram-se motivos favoráveis a um alargamento dos conceitos elementares da autorregulação profissional do jornalismo.

Enquanto a fundamentação da heterorregulação decorre diretamente de disposições legais, a legitimidade de um modelo regulador fundado numa matriz eletiva e moral implica o reconhecimento generalizado do seu papel de intervenção, fomentando uma relação de confiança entre as partes interessadas (Camps, 2004). 0 imperativo de cooperação é tão mais claro quanto seja patente a natureza voluntária do sistema (Zlatev, 2011). Esta dinâmica de "governance participativa dos media" tende a aumentar os níveis de credibilidade do sistema regulador, como também a renovar a legitimidade democrática do jornalismo (Rossi e Meier, 2012).

Devido às características muito particulares do percurso de consolidação profissional dos jornalistas, o estabelecimento de relações de parceria e de debate alargado com outros atores configura-se condição essencial para atingir o potencial que a regulação da informação detém no dinamismo das condições profissionais e laborais.

Os rumos de mutação do mercado da comunicação têm acentuado a relevância da intervenção reguladora do Estado, através do controlo e supervisão dos aspetos técnicos e económicos da regulação (losifidis, 2011; Puppis 2013), ou fornecendo o referencial formal e legal às exigências de pluralismo, independência editorial e interesse público (Puddephatt, 2011; Bernier, 2014). As autoridades públicas configuram-se, portanto, uma componente fundamental da governance dos media, a que os modelos alternativos devem necessariamente atender, fomentando redes de articulação e cooperação. Embora a interposição governamental, na regulação dos 
conteúdos e processos, pressuponha o risco de captura desses espaços, evidenciaram-se anteriormente modos menos intrusivos de intervenção estatal, destinados a estimular uma regulação alternativa dos media (Puppis et al., 2012). Os tipos de suporte financeiro infraestrutural ou mesmo estatutário figuram-se motivos pertinentes para abdicar de visões anacrónicas, excludentes do Estado, convidando-0 a assumir, em parceria, a dinamização de novos espaços de responsabilização do jornalismo.

Considerar que um modelo autorregulador do jornalismo pode concretizar efetivamente a sua função de persuasão e sanção moral num sistema destituído da intervenção dos proprietários não é apenas ingénuo. É inclusivamente perigoso, na medida em que se pode, em última análise, sancionar apenas jornalistas por comportamentos que têm origem ou se estendem pela dimensão mais vasta da empresa ou meio de comunicação social. Resultando a pertinência da sanção moral do poder retificativo, pedagógico e discursivo das suas deliberações, vê-se acrescida a necessidade da participação dos proprietários e dos responsáveis editoriais.

À luz do que Sanderson (2011) identifica serem as vantagens da corregulação, a participação ativa dos diferentes elementos do sistema mediático pende para suprimir, ou mesmo anular, o risco de captura da regulação.

Finalmente, no contexto de proliferação de fórmulas mais participativas de intervenção e criticismo (Bernier, 2014), a parceria entre a indústria e o público torna-se fundamental. Em primeiro lugar, busca assegurar o espaço da opinião profissional neste novo quadro. Em segundo, procura imprimir significado às vagas de criticismo emergentes no espaço digital. Por último, a promoção do debate alargado torna-se um pré-requisito substancial para a concretização do ideal da polis dos media proposto por Silverstone (2007).

\section{Síntese CONCLusiva}

Historicamente, a consolidação da identidade profissional dos jornalistas norteia-se por um processo de caraterísticas pouco definidas ou fechadas, culminando numa profissão de carácter aberto e de monopólio simbólico. A emergência de um novo ambiente comunicacional é acompanhada por novas lógicas concorrenciais que ameaçam diluir, transfigurar ou adulterar as funções essenciais da atividade. Neste contexto, figura-se essencial um debate profissional sobre as fronteiras e alicerces da profissão.

Paralelamente, observou-se como o processo de evolução do sistema regulatório do jornalismo português, se inscreve em linhas de complexidade e inconstância que tendem a fragilizar, ainda mais, o poder institucional dos jornalistas. A posição dos jornalistas desvenda traços de vontade e de iniciativa de reorganização deste enquadramento regulador. À luz do que são as tendências contemporâneas de responsabilização do jornalismo, e dos desafios da profissão, importa, pois, que este não seja um debate hermético, mas que convoque os diferentes agentes do sistema mediático.

"Regulação participada" e "regulação em parceria" são apresentados como dois conceitos, não apenas descritivos, como também propositivos da necessidade de, não só recentrar esta discussão a partir da dimensão profissional, como também de convocar a sociedade para esse debate. Em última análise, estes dois eixos serão fundamentais para confrontar os desafios contemporâneos que se colocam ao jornalismo e às sociedades democráticas. 


\section{RefERÊnCIAS Bibliográficas:}

Bartle, I. \& Vass, P. (2007). Self-regulation within the regulatory State: towards a new regulatory paradigm? Public Administration, 85(4), 885-905.

Berger, G. (2010). The struggle for press self-regulation in contemporary South Africa: charting a course between an industry charade and a government doormat. Communicatio: South African Journal for Communication Theory and Research, 36(3), 289-308.

Bernier, M. F. (2014). Éthique et déontologie du journalisme. Quebec: Presses de I'Université Laval.

Bruns, A. (2010). News produsage in a pro-am mediasphere: why citizen journalism matters. In G. Meikle \& G. Redden (Eds.) News online: transformations and continuities. Londres: Palgrave Macmillan.

Camponez, C. (2011). Deontologia do jornalismo: a autorregulação frustrada dos jornalistas portugueses: 1974-2007. Coimbra: Almedina.

Carey, J. W. (1974). Journalism and criticism: the case of an undeveloped profession. The Review of Politics, 36(2), 227-249.

Dvorkin, J. (2015, 27 de abril). Why click-bait will be the death of journalism. PBS. Retrieved from https://www.pbs.org/newshour/economy/what-you-dont-know-about-click-baitjournalism-could-kill-you.

O'Donnell, P., Zion, L., \& Sherwood, M. (2016). Where do journalists go after newsroom job cuts?.Journalism Practice, 1911, 35-51.

Puppis, M. (2013). Press Governance: A New Concept for Analyzing Press Regulation. In P. Murschetz (Ed.) State aid for newspapers: theories, cases, actions. Berlim: Springer.

Puppis, M., Micova, S. B. \& Tambini, D., 2012. Reforming the PCC: lessons from abroad. In S. Broughton Micova and D. Tambini (Eds.) Media policy brief. Londres: The London School of Economics and Political Science.

Stanistreet, M. (2011, 16 de novembro). NUJ chief Michelle Stanistreet's statement to the Leveson inquiry. Guardian. Retrieved from https://www.theguardian.com/media/2011/ nov/16/michelle-stanistreet-leveson-inquiry

Viner, K. (2017, 16 de novembro). A mission for journalism in a time of crisis. Guardian. Retrieved from https://www.theguardian.com/news/2017/nov/16/a-mission-for-journalism-in-a-time-of-crisis

João Miranda - Investigador no Centro de Estudos Interdisciplinares do Século XX e professor na Faculdade de Letras da Universidade de Coimbra, João Miranda é autor da tese de mestrado "Os efeitos do novo paradigma socioprofissional do jornalismo sobre as práticas de ética e deontologia". Encontra-se a terminar a sua tese de doutoramento, subordinada à contextualização da autorregulação profissional do jornalismo português no plano europeu. 